\title{
Corroded Subsea Pipelines Burst Pressure Prediction Utilizing Finite Element Data Using ANN
}

\author{
Mohd Fakri Muda ${ }^{1}$, Mohd Hisbany Mohd Hashim ${ }^{2, *}$, Mohd Khairul Kamarudin ${ }^{2}$, Mohd Hairil Mohd ${ }^{3}$, \\ Marzuki Abdul Rahman ${ }^{1}$

\begin{abstract}
${ }^{1}$ School of Civil Engineering, Universiti Teknologi MARA Cawangan Pahang, Kampus Jengka, 26400 Jengka, Pahang, Malaysia
${ }^{2}$ School of Civil Engineering, College of Engineering, Universiti Teknologi MARA, 40450 Shah Alam, Selangor, Malaysia

${ }^{3}$ Department of Maritime Technology, Universiti Malaysia Terengganu, Malaysia
\end{abstract}

Received May 8, 2021; Revised October 19, 2021; Accepted November 22, 2021

\section{Cite This Paper in the following Citation Styles}

(a): [1] Mohd Fakri Muda, Mohd Hisbany Mohd Hashim, Mohd Khairul Kamarudin, Mohd Hairil Mohd, Marzuki Abdul Rahman , "Corroded Subsea Pipelines Burst Pressure Prediction Utilizing Finite Element Data Using ANN," Civil Engineering and Architecture, Vol. 10, No. 1, pp. 334-344, 2022. DOI: 10.13189/cea.2022.100128.

(b): Mohd Fakri Muda, Mohd Hisbany Mohd Hashim, Mohd Khairul Kamarudin, Mohd Hairil Mohd, Marzuki Abdul Rahman (2022). Corroded Subsea Pipelines Burst Pressure Prediction Utilizing Finite Element Data Using ANN. Civil Engineering and Architecture, 10(1), 334-344. DOI: 10.13189/cea.2022.100128.

Copyright $\odot 2022$ by authors, all rights reserved. Authors agree that this article remains permanently open access under the terms of the Creative Commons Attribution License 4.0 International License

\begin{abstract}
The Engineering industry is constantly exploring an effective and fast-solving method for complicated engineering problems. The adaptation of artificial intelligent technology can diminish the time-consuming of conventional analysis methods, especially in offshore engineering. For that reason, this study is pursued to build a prediction model to predict the residual strength of API 5L X42 subsea pipelines. An artificial neural network is used as an analytical medium in developing the prediction model. Three (3) physical shapes of corrosion data with diverse corrosion level are designed as input data based on the corroded subsea pipelines of true 2009 historical inspection data of South China Sea. The output data are obtained from the finite element analysis to produce the burst pressure data. The performance model is evaluated using mean squared error (MSE) and mean absolute error (MAE) which results in 9.13 x 10-5 and 0.005499 respectively for the optimum model. The predicted output shows significant similarity in line with the finite element output for validation purposes. This model is expected to provide quick prediction reliability of subsea pipelines to the engineers and reduce or eliminate massive analysis work.
\end{abstract}

Keywords Subsea Pipelines, Residual Strength, Corrosion, Prediction, ANN, FEM

\section{Introduction}

The structural reliability of pipelines system is one of the major contributors to the efficiency of productivity in the oil and gas industries. Therefore, high integrity of the pipelines and pre-rehabilitation is crucial to prolong the industry's productivity capabilities. One of the factors that concern engineers the most is corrosion and parameters related to it. An in-depth study covering numerical, empirical, and modelling in this field has been carried out by many researchers [1]-[4] focusing on various parameters that cause corrosion. Nowadays, the research method with regards to the prediction failure model is rising due to its boundless potential to detect and repair compared to the conventional inspection method.

Long-term corrosion will cause a material loss on the pipelines that consequently reduce the wall thickness. Corrosion for underwater pipelines especially subsea pipelines is categorized into seven types of defects, that is axial grooving, axial slotting, circumferential grooving, circumferential slotting, general, pinhole and pitting corrosion. All these types of corrosion reduce the strength of the pipelines which may put the service to a complete stop if no repair measures are taken. A failed pipeline is identified by determining the remaining burst pressure of the corroded pipelines and comparing with the Estimate Repair Factor, ERF. Several established codes such as ASME B31G, Modified ASME B31G, DNV RP F101, 
PCORRC, Shell 92 and few others have been used to determine the residual burst pressure of the corroded pipelines depending on the criteria of the corrosion factor of the pipelines. These codes provide different output values which affect the remaining strength and lifespan of the corroded pipelines.

For the past few years, many researches have been carried out to study the failure assessment on corroded pipeline models [1], [2], [5], [6]. These researchers focused on the equation method and finite element analysis to evaluate the residual strength of the defected pipelines. Input analysis involving historical inspection data was covered by Al-Amin[7], Din[8], Sinha[9], Senouci et al.[10], El-Abbasy et al.[11], Miran et al.[12] and $\mathrm{Xu}$ et al.[13]. All of them except Al-Amin[7] are using an artificial neural network (ANN) as an analysing tool as it is more effective for randomized data. Residual burst pressure prediction of corroded pipelines is developed profoundly by Wen et al.[14] using ANN. But the output data of the pipelines burst pressure is measured by using ASME B31G codes as it gives the lowest value compared to other codes [15]. This will result in less accuracy in forecasting the reliability of the pipeline's services. Therefore, this paper presents the prediction of residual burst pressure in multiple levels of corrosion by using ANN. The burst pressure output data is tabulated from finite element, $\mathrm{FE}$ analysis as it is the most precise method in determining the remaining strength of the corroded pipelines that will be valuable tools in offshore pipelines construction.

\section{Review of Study}

The factor that causes corrosion has been concerned of engineers for centuries. Many studies involving corrosion factors have been carried out such as Yang et al.[5] who studied the abnormal condition of corroded pipelines by Bow-Tie analysis and Al-Amin[7] who focus on the reliability of corroding pipelines based on inspection data. Corrosion may be formed into several types of defects which have been studied extensively by Chen et al.[16] for interacting corrosion defects, Li et al.[17] on effects of interaction defects, Mohd and Paik[18] on corrosion progress characteristic, Ilman and Kusmono[19] on internal corrosion in oil subsea pipelines and more. The main outcome of the study is finding the correlation between types of corrosion and the effects on the strength of the corroded pipelines. As indicated by Mohd et al.[2], all of the researches emphasize that the most hazardous defect is pitting corrosion which is classified by (1) [29], where $\mathrm{W}, \mathrm{L}$ and $\mathrm{t}$ stand for the width, length and thickness of the defect area.

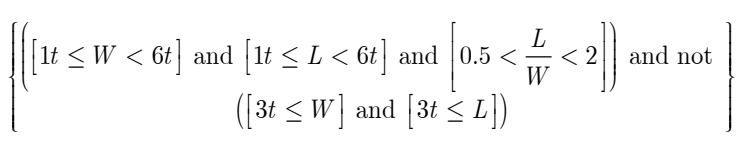

Their research focuses on the effects of the corrosion factors on the physical properties related to the pipeline's body based on several models established to fully understand the behaviour of the core factor itself.

The diversity of research regarding corrosion moves engineers a step further in this area by developing a prediction model. Prediction model provides useful information to engineers to find the root problem and early pre-rehabilitation methods that can be taken. However, random, non-linear and complexity of corrosion data make the prediction of a model difficult and unprecise in which can be overcome by using an artificial neural network [20]. Din[8] developed an ANN model for corrosion growth prediction by using in-line inspection data. The developed model publishes of mean square error (MSE) 0.0102 and $\mathrm{R}^{2}$ of 0.999. Another researcher, Senouci et al. [10] and El-Abbasy et al. [11] design a model for predicting the failure of oil pipelines by using factors other than corrosion and ANN tools for the design model. Many other researchers successfully using ANN in their research to develop a prediction model such as Kurtgoz et al.[21] on biogas engine estimation; El-Abbasy et al.[11] on ANN prediction of the existing condition of pipelines for prioritization of inspection and rehabilitation; and Moghaddasi and Noorian-Bidgoli[22] on ANN prediction of surface settlement, etc.

ANN functions as much as human neurons and is able to analyse various rule extraction algorithm to solve and develop a prediction model[23]. The algorithm needs specific input and output data to develop the target model. El-Abbasy et al.[11] research work data are created based on historical inspection data in Qatar with three different types of subsea pipelines. While Xu et al.[13], Oh et al.[24] and Sinha[9] input data based on experimental data of X80, X65 and X60 steel pipelines. The design of each model is limited to the types of pipelines study only and none X42 pipelines were covered except by Mohd et al.[25] and recently by Wen et al.[14] that used numerical analysis and ANN as for the predictive model. Both researchers use modified ASME B31G codes as output data for their research model in determining residual burst pressure, $\mathrm{P}_{\mathrm{f}}$ of the pipelines.

The burst pressure of corroded pipelines normally can be determined by referring to four establish design codes; ASME B31G, PCORRC, Modified ASME B31G and DNV RP F101. Table 1 shows the residual burst pressure equation for single/spitting types of corrosion [15]. All four design codes are well known to determine the remaining strength of corroded pipelines in different criteria depending on the pipelines studied. Bin Mohd et al. [15] studied residual burst pressure using five design codes and finite element analysis. Specific minimum yield strength, SMYS is used in ASME B31G [26] to determine the burst pressure where $M$ stands for bulging stress magnification factor. While PCORRC [27] and DNV RP F101 [28] used ultimate tensile strength, $\sigma_{\mathrm{u}}$ and length correction factor, $\mathrm{Q}$ needs to be considered. The study 
found that ASME B31G releasing the lowest burst pressure value and DNV RP F101 [28] closest to the finite element analysis output [2] as shown in Fig.1. As such, as can be concluded from reviewing several studies, there exists a wide gap of prediction value between prediction output based on ASME codes and true value by validating FE model. Precise data need to be considered to design and analyse a pre-rehabilitation for corroded pipelines, and for this research, a prediction based on FE data using ANN is carried out.

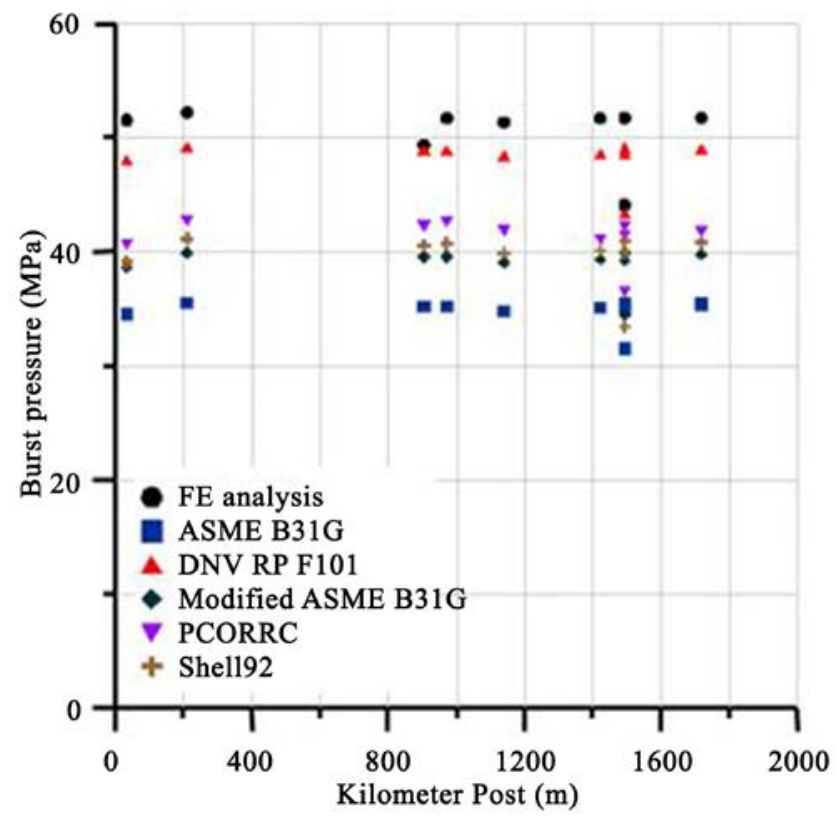

Figure 1. Burst pressure with different codes and by FE for pipelines in the year 2009 [15]

Table 1. The equation for residual burst pressure, $\mathrm{P}_{\mathrm{f}}$

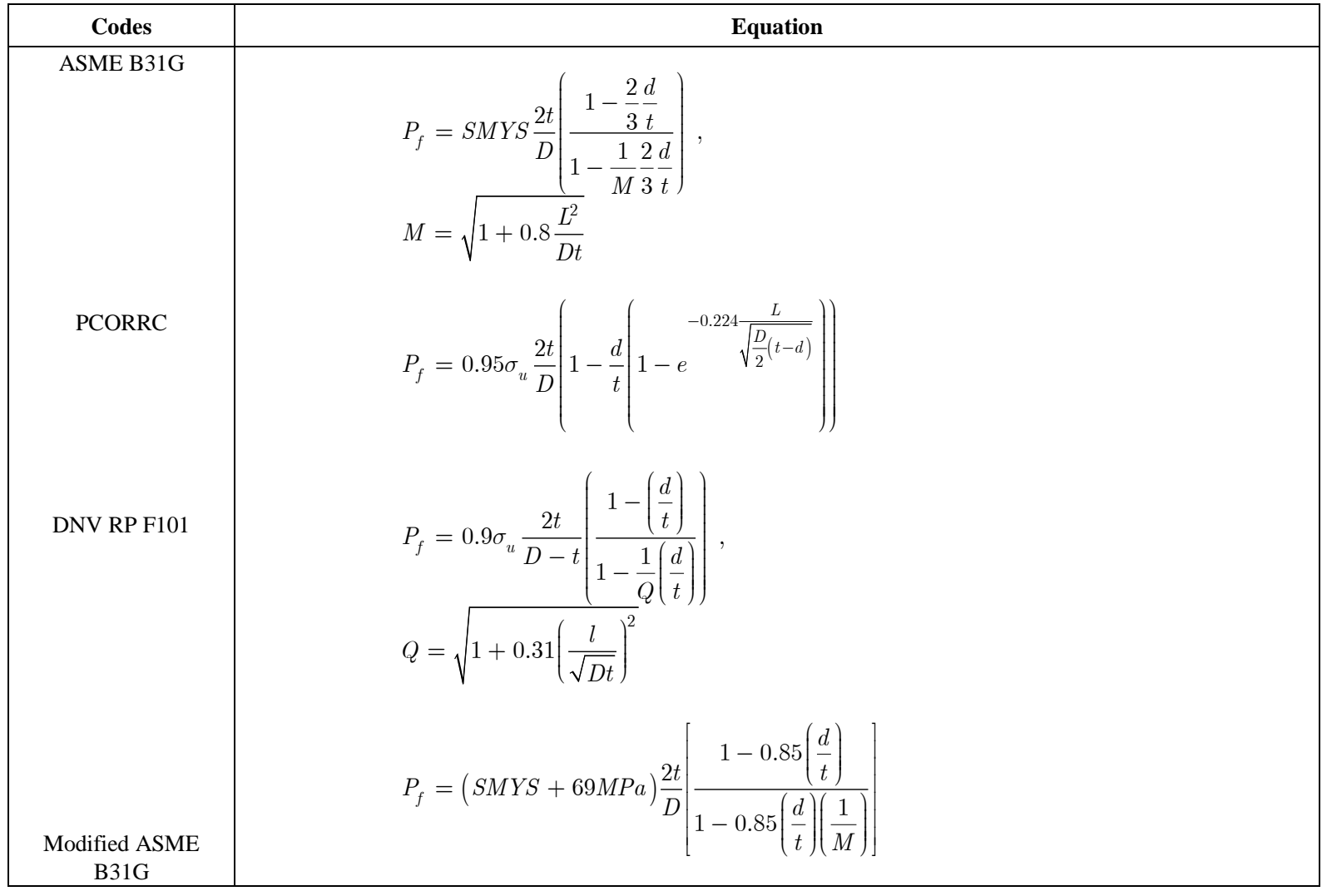




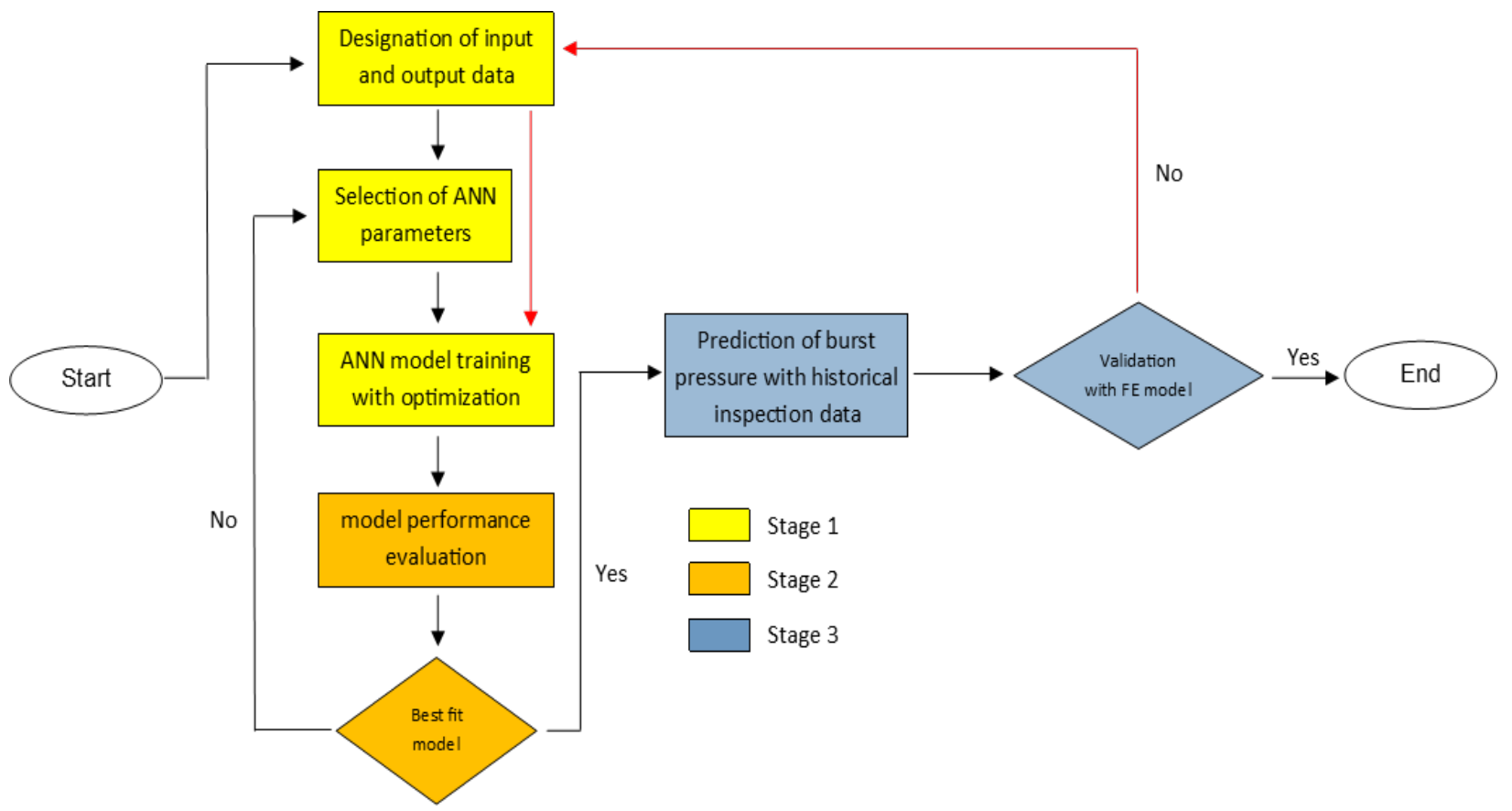

Figure 2. Research methodology diagram

\section{Methodology}

The methodology of this study is divided into three stages. The development of the ANN model, models performance evaluation and burst pressure prediction validation. The research methodology diagram is shown in Fig.2.

\subsection{Input Data and Output Data}

Table 2. General information of the target pipelines[15]

\begin{tabular}{|c|c|}
\hline Parameters & Detail \\
\hline Types & Gas pipelines \\
Outer diameter, mm & 168.275 \\
Wall thickness, mm & 9.5 \\
Total length, $\mathrm{m}$ & 2543.53 \\
Age, year & 19 \\
Material grade & API 5L X42 \\
Max. allowable operating & 13.1 \\
pressure, MPa & 1990 \\
Date of commissioning, year & 210.7 \\
Young's modulus, E (GPa) & 0.3 \\
Poisson's ratio, $v$ & 290 \\
Yield strength, $\sigma_{\mathbf{y}}(\mathrm{MPa})$ & 495 \\
Tensile Strength, $\sigma_{u}(\mathrm{MPa})$ & \\
\hline
\end{tabular}

The key to an efficient prediction model of ANN is the input data. Resilient data will publish more accurate output and high accuracy model. The main research data for this study is true historical inspection data of South China Sea dated in 2009 from a local oil and gas company in Malaysia. Table 2 shows the information of the pipelines[15].

The data contain five parameters which are distance, position, length, width, and depth. Distance means the distance of the affected area measured from the base start of the inspection area to the corroded area. The last point of inspections/readings is at distance of $2543.53 \mathrm{~m}$ and the total inspections point is 330 points. The readings were analysed to configure input ANN data by dividing the data into several classes. The anomaly of the parameters is shown in Fig.3. The historical inspection data recorded the worst corrosion level is at $50 \%$ at point $1420.38 \mathrm{~m}$ from the base point. El-Abbasy et al.[11] suggested that corrosion levels beyond $60 \%$ require major rehabilitation or replacement immediately. But this decision also depends on the value of Estimate Repair Factor, ERF (2). MAOP is the maximum allowable operating pressure of the designated pipelines. ERF represents the ratio of the pipeline's pressure which uses a value of ' 1 ' as an indicator of perfect pipeline fitness. ERF less than one is needed to consider the defect is acceptable. For that, the level of corrosion depth as input ANN data is focused on the range of $0 \%$ to $80 \%$. As for the dimension of the defected area, the size is tabulated by referring to the inspection data as the gap in between the classes is not too outlier to each other and to minimize the models of FE.

$$
E R F=\frac{M A O P}{P_{f}}
$$




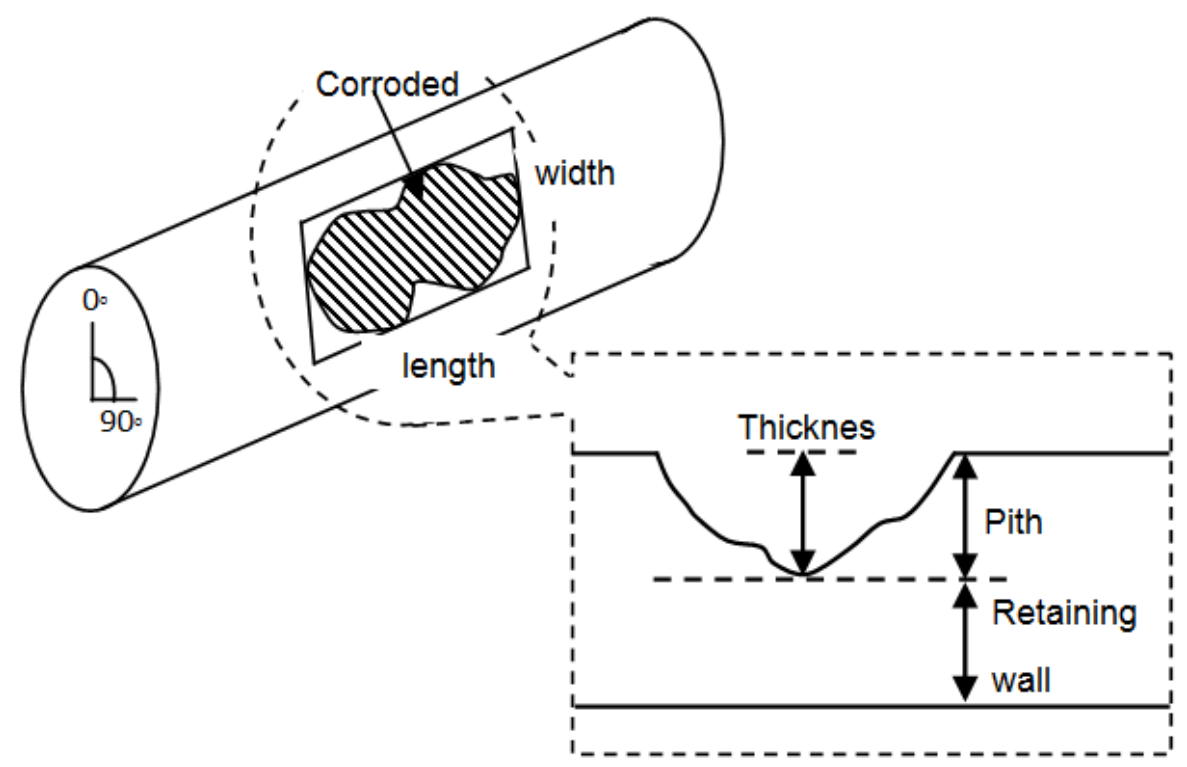

Figure 3. Anomaly of the corroded area

The output data of the model are residual burst pressure, $\mathrm{P}_{\mathrm{f}}$. The burst pressure is determined by FE analysis and performed using Abaqus 6.14. A Three-dimensional (3D) FE model was developed first and validated with previous studies to ensure the model is precise to mimic the behaviour of the corroded pipelines. Then, the similar model is edited and run to the ANN input data to form an output ANN data and stress-strain behaviour database as shown in Fig.4. The material properties assigned to the FE models are taken from research done by Mohd et al.[2] as it uses the same research data. The input and output ANN data for the $15 \%$ level of corrosion is listed in Table 3 and the list continues for $30 \%, 40 \%, 50 \%, 60 \%$ and $80 \%$.

Table 3. Part of input data for model ANN

\begin{tabular}{|c|c|c|c|c|}
\hline \multirow{2}{*}{ Name } & \multicolumn{3}{|c|}{ Input } & $\begin{array}{c}\text { Output } \\
\text { (FE) }\end{array}$ \\
\cline { 2 - 5 } & $\begin{array}{c}\text { Depth } \\
\text { (\%) }\end{array}$ & $\begin{array}{c}\text { Length } \\
\text { (mm) }\end{array}$ & $\begin{array}{c}\text { Width } \\
\text { (mm) }\end{array}$ & $\begin{array}{c}\text { Burst } \\
\text { Pressure } \\
\text { (MPa) }\end{array}$ \\
\hline $\begin{array}{c}\text { RX42 } \\
\text { (no corrosion) }\end{array}$ & 0 & 0 & 0 & 58.8345 \\
\hline RX42-15-1 & 15 & 200 & 200 & 53.3159 \\
\hline RX42-15-2 & 15 & 100 & 100 & 55.9144 \\
\hline RX42-15-3 & 15 & 75 & 75 & 56.9438 \\
\hline RX42-15-4 & 15 & 50 & 50 & 57.8861 \\
\hline
\end{tabular}
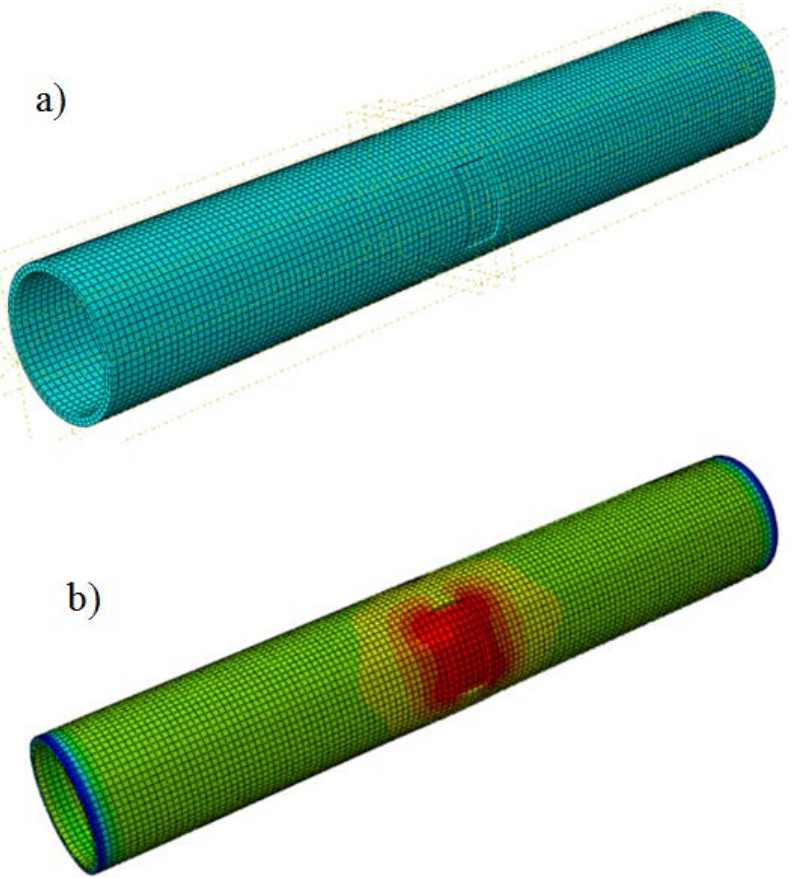

Figure 4. a) 3D FE model scale b) FE model after analyzing. 


\subsection{Model Performance Evaluation and Prediction}

The development of the ANN model was initiated with the designation of input and output data in subtopic 2. The ANN parameter is selected by trial and error which can provide the highest performance. The selected parameters are shown in Table 4 and Fig.5. The neurons of ANN don't have to be organized as a tree or hierarchy and may intersect with each other, thus creating an artificial neural network. The connections between neurons also are constantly changing as new data is fed into the system, meaning that ANN does not require retraining every time input data changes. After that, the training model is conducted, and the performance is measured by mean square error (MSE) and mean absolute error (MAE). be selected as a research model. This can prevent the model with low performance is selected to be a research choice model. A series of 20 cycles of set training is conducted to observe if the model succeeds to produce an optimum model for each training cycle. To determine the number of training required to achieve optimum performance is difficult for any ANN models. Therefore, the optimization method will be applied. Optimization means the training will be repeated for a certain number of times and the most optimum model will be chosen as research model.

A successful model needs to be justified by validation process. The validation is very important to determine the acceptability of the model's output. For the ANN model, the validation is determined by comparing the model's output from the historical data input with its FE output analysis. The input prediction source is shown in Table 5 as five critical points are taken from the historical inspection data of subsea pipelines systems. If the differences percentage error is greater than $5 \%$, the input data of the training ANN model need to be add-up until the error below $5 \%$ is achieved. From the prediction output data, the assessment of failure pipe or Estimate Repair Factor, ERF can be determined by (2).

*sym $=$ symbol

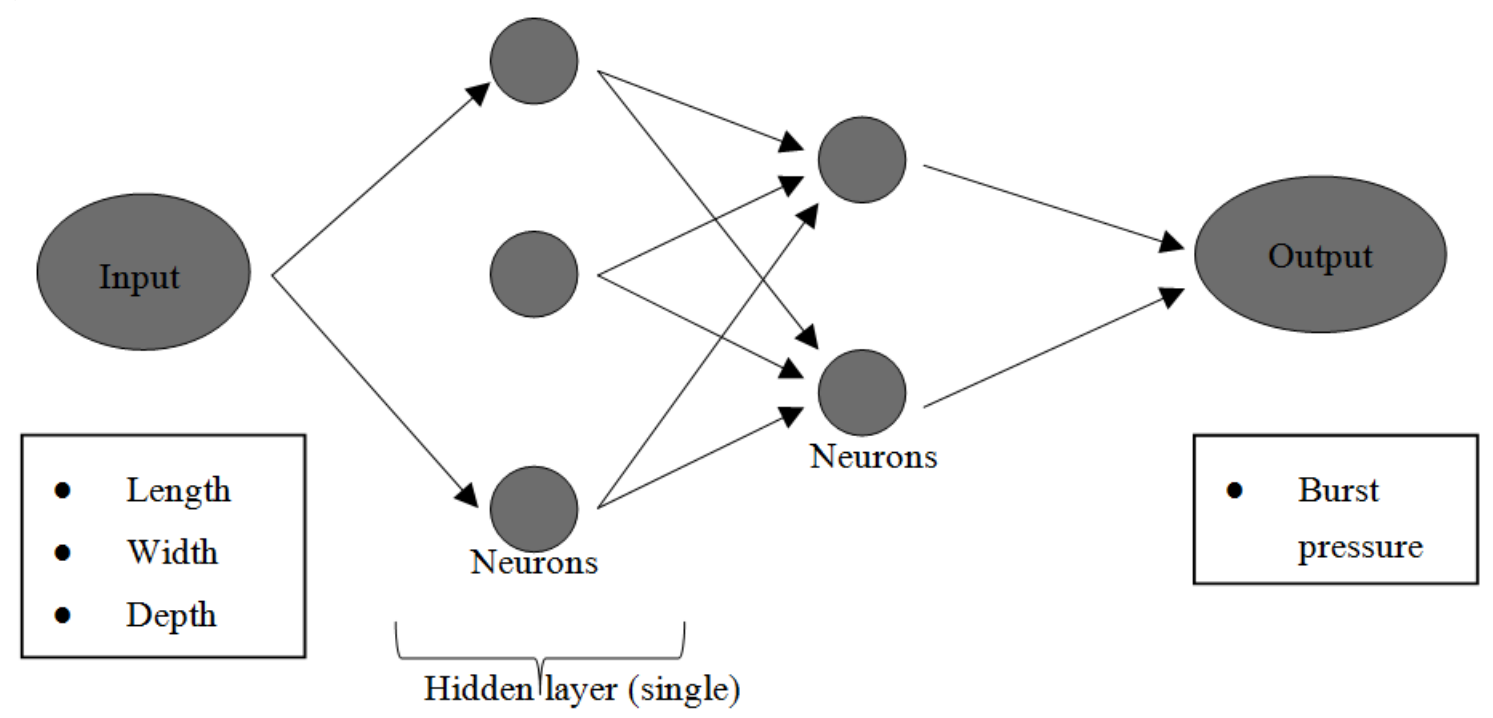

Hidden layer (double)

Figure 5. Diagram of the ANN model

Table 4. Parameters of the ANN model

\begin{tabular}{|c|c|c|c|c|c|c|c|c|c|}
\hline & $\begin{array}{c}\text { Network } \\
\text { Data division } \\
\text { Normalization }\end{array}$ & \multicolumn{8}{|c|}{$\begin{array}{l}\text { Feedforward network } \\
\text { Random } \\
\text { Average method }\end{array}$} \\
\hline \multicolumn{10}{|c|}{ Selected design parameter } \\
\hline \multicolumn{2}{|r|}{ Training function } & \multicolumn{2}{|c|}{ Activation function } & \multicolumn{2}{|c|}{ Hidden layer } & \multicolumn{2}{|c|}{ No of neuron } & \multicolumn{2}{|c|}{ Data distribution } \\
\hline Sym & Details & Sym & Details & Sym & Details & Sym & Details & Sym & Details \\
\hline A & Levenberg-Marquardt & $\mathrm{D}$ & Purelin & \multirow[b]{2}{*}{$\mathrm{H}$} & \multirow[b]{2}{*}{ Single } & $\mathrm{J}$ & 10 & \multirow[b]{2}{*}{$\mathrm{N}$} & \multirow{2}{*}{$\begin{array}{c}\text { Training }=60 \% \\
\text { Validation }=20 \% \\
\text { Testing }=20 \%\end{array}$} \\
\hline B & $\begin{array}{c}\text { BFGS } \\
\text { Quasi- Newton }\end{array}$ & E & Tansig & & & K & 5 & & \\
\hline $\mathrm{C}$ & Scaled Conjugate Gradient & $\mathrm{F}$ & Logsig & \multirow{2}{*}{ I } & \multirow{2}{*}{ Double } & $\mathrm{L}$ & $\begin{array}{l}1^{\text {st }} \text { layer }=5 \\
2^{\text {nd }} \text { layer }=2\end{array}$ & \multirow{2}{*}{$\mathrm{O}$} & \multirow{2}{*}{$\begin{array}{c}\text { Training }=70 \% \\
\text { Validation }=15 \% \\
\text { Testing }=15 \%\end{array}$} \\
\hline $\mathrm{D}$ & Resilient Backpropagation & G & Poslin & & & M & $\begin{array}{c}1^{\text {st }} \text { layer }=10 \\
2^{\text {nd }} \text { layer }=2\end{array}$ & & \\
\hline
\end{tabular}


Table 5. Validation data

\begin{tabular}{|c|c|c|c|c|}
\hline No & Label & $\begin{array}{c}\text { Distance } \\
(\mathbf{m})\end{array}$ & Position & $\begin{array}{c}\text { Depth } \\
(\mathbf{\%})\end{array}$ \\
\hline 1 & $\mathrm{X} 42-50 \mathrm{M}-1$ & 1420.38 & 9.54 & 50 \\
\cline { 2 - 5 } 2 & $\mathrm{X} 42-49 \mathrm{M}-1$ & 1717.77 & 12.36 & 49 \\
\cline { 2 - 5 } 3 & $\mathrm{X} 42-41 \mathrm{M}-3$ & 32.51 & 12.4 & 41 \\
\cline { 2 - 5 } 4 & $\mathrm{X} 42-41 \mathrm{M}-1$ & 1492.45 & 3.14 & 41 \\
\cline { 2 - 5 } 5 & $\mathrm{X} 42-41 \mathrm{M}-2$ & 1492.45 & 3.14 & 41 \\
\hline
\end{tabular}

\begin{tabular}{|c|c|c|c|c|}
\hline No & Depth (mm) & $\begin{array}{c}\text { Length } \\
(\mathbf{m m})\end{array}$ & $\begin{array}{c}\text { Width } \\
(\mathbf{m m})\end{array}$ & $\begin{array}{c}\text { Burst pressure, FE } \\
\text { (MPa) }\end{array}$ \\
\hline 1 & 4.75 & 15 & 51 & 57.6335 \\
\hline 2 & 4.655 & 12 & 59 & 57.9347 \\
\hline 3 & 3.895 & 23 & 51 & 57.2455 \\
\hline 4 & 3.895 & 13 & 15 & 58.3059 \\
\hline 5 & 3.895 & 56 & 117 & 50.4116 \\
\hline
\end{tabular}

\section{Results and Discussion}

\subsection{ANN Model Performance}

The performance of the ANN model is monitored by the value of MSE and MAE. Fig.6 shows the model number versus MSE and MAE recorded by one single ANN model running through the optimization method. A total of 50 models are trained continuously resulting in different MSE and MAE values. '0' MSE value denotes a perfect model without error. The most optimum model is model 38 with MSE and MAE values of $3.609 \times 10^{-4}$ and 0.012 respectively. Then, to prove that each training set can produce an optimum model, 10 sets of training cycles have been conducted and each optimum model has MSE and MAE under 0.03 which proves near-perfect models are generated in each cycle. Table 6 shows the optimum model performance and comparison of burst pressure between FE data and output data from the ANN model. The ANN model gives the output values with a significant small error under $5 \%$ between both data outputs.

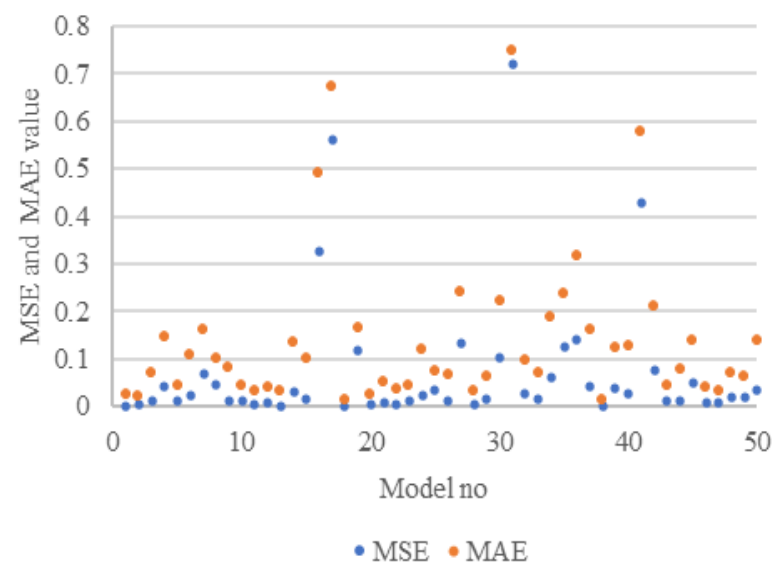

Figure 6. Graph model no. versus MSE and MAE in a single training
Table 6. Accuracy of each optimum model and output comparison

\begin{tabular}{|c|c|c|}
\hline \multicolumn{3}{|c|}{ Performance of optimum model } \\
\hline Training cycle & MSE & MAE \\
\hline 1 & 0.000360 & 0.012386 \\
2 & 0.0005226 & 0.008967 \\
3 & 0.0004629 & 0.006711 \\
4 & 0.0006224 & 0.009220 \\
5 & 0.0013545 & 0.023864 \\
6 & 0.0007662 & 0.014007 \\
7 & 0.0005728 & 0.017548 \\
8 & 0.0006604 & 0.011140 \\
9 & 0.0001644 & 0.006735 \\
10 & 0.0004506 & 0.013767 \\
\hline
\end{tabular}

\begin{tabular}{|c|c|c|c|}
\hline \multicolumn{4}{|c|}{ ANN output comparison } \\
\hline Model & $\begin{array}{c}\boldsymbol{P}_{\mathbf{f}} \\
\text { FE data (MPa) }\end{array}$ & $\begin{array}{c}\boldsymbol{P}_{\mathbf{f}} \\
\text { ANN model (MPa) }\end{array}$ & $\begin{array}{c}\text { Error } \\
\mathbf{\%}\end{array}$ \\
\hline RX42-15-1 & 53.3159 & 52.8838 & 0.81035 \\
RX42-15-3 & 56.9438 & 56.1993 & 1.30732 \\
RX42-30-1 & 45.1565 & 44.8769 & 0.61897 \\
RX42-30-4 & 55.4427 & 55.1440 & 0.53859 \\
RX42-40-1 & 39.3858 & 39.2492 & 0.34670 \\
RX42-40-2 & 45.0597 & 44.9930 & 0.14790 \\
RX42-60-1 & 27.1105 & 27.0875 & 0.08451 \\
RX42-60-2 & 34.9081 & 33.8588 & 3.00576 \\
RX42-80-1 & 14.1367 & 14.3937 & -1.81835 \\
RX42-80-2 & 22.128 & 22.1499 & -0.09926 \\
\hline
\end{tabular}

\subsection{ANN Model Designation}

The ANN model is designed by combining different ANN design parameters in Table 4 to achieve a model with the highest performance. The input for the model is three inputs which are the area (width and length) and depth of defected area which influenced the burst pressure value. Table 7 shows the performance of the designated model by different combinations of the model parameters. Model 11 gives the most accurate performance by producing the lowest index of MSE and MAE. However, to justify the model that can fit the research problem, the models need to be analysed in terms of the prediction ability in determining the burst pressure of the corroded subsea pipelines.

Table 7. Performance of the ANN model

\begin{tabular}{|c|c|c|c|}
\hline Model & $\begin{array}{c}\text { Design } \\
\text { Parameter }\end{array}$ & MSE & MAE \\
\hline 1 & A,D,H,J,N & 0.0272363 & 0.128717 \\
\hline 2 & A,E,H,J,N & 0.000927027 & 0.019066 \\
\hline 3 & A,E,I,M,O & 0.000492541 & 0.016111 \\
\hline 4 & A,F,H,J,N & 0.001286767 & 0.018204 \\
\hline 5 & A,G,H,J,N & 0.000847036 & 0.021386 \\
\hline 6 & B,F,H,J,N & 0.001890344 & 0.034788 \\
\hline 7 & C,F,H,J,N & 0.002298804 & 0.035964 \\
\hline 8 & D,F,H,J,N & 0.003871557 & 0.041186 \\
\hline 9 & A,F,H,K,N & 0.000233135 & 0.009648 \\
\hline 10 & A,F,H,K,O & 0.000199195 & 0.009079 \\
\hline $\mathbf{1 1}$ & A,F,I,L,O & $\mathbf{9 . 1 3 E - 0 5}$ & $\mathbf{0 . 0 0 5 4 9 9}$ \\
\hline 12 & A,F,I,M,O & 0.000224123 & 0.006739 \\
\hline
\end{tabular}




\subsection{Failure Pipe Prediction}

Table 8. Burst pressure prediction validation.

\begin{tabular}{|c|c|c|c|c|c|}
\hline \multirow{2}{*}{$\begin{array}{c}\text { Distance } \\
\text { (m) }\end{array}$} & \multicolumn{5}{|c|}{ Burst Pressure (MPa) } \\
\hline & FE & $\begin{array}{c}\text { Model } \\
11\end{array}$ & $\begin{array}{c}\text { Model } \\
11-1 \\
\end{array}$ & $\begin{array}{c}\text { Model } \\
11-2 \\
\end{array}$ & $\begin{array}{c}\text { Model } \\
11-3\end{array}$ \\
\hline 1420.38 & 57.63 & 11.31 & 24.05 & 53.35 & 57.40 \\
\hline 1717.77 & 57.93 & 10.76 & 23.67 & 57.60 & 55.63 \\
\hline 32.51 & 57.24 & 54.97 & 58.53 & 58.37 & 58.89 \\
\hline 1492.45 & 58.30 & 57.82 & 58.85 & 58.88 & 59.17 \\
\hline 1492.45 & 50.41 & 53.36 & 57.63 & 56.87 & 50.33 \\
\hline \multirow{2}{*}{$\begin{array}{c}\text { Distance } \\
\text { (m) }\end{array}$} & \multicolumn{5}{|c|}{ Error (\%) } \\
\hline & FE & $\begin{array}{c}\text { Model } \\
11\end{array}$ & $\begin{array}{c}\text { Model } \\
11-1 \\
\end{array}$ & $\begin{array}{c}\text { Model } \\
11-2\end{array}$ & $\begin{array}{c}\text { Model } \\
11-3\end{array}$ \\
\hline 1420.38 & 57.63 & 80.37 & 58.25 & 7.42 & 0.39 \\
\hline 1717.77 & 57.93 & 81.42 & 59.12 & 0.56 & 3.96 \\
\hline 32.51 & 57.24 & 3.96 & -2.25 & -1.97 & -2.88 \\
\hline 1492.45 & 58.30 & 0.83 & -0.93 & -0.99 & -1.49 \\
\hline 1492.45 & 50.41 & -5.86 & -14.32 & -12.81 & 0.15 \\
\hline
\end{tabular}

Prediction input for five critical points of historical inspection data is loaded to the optimum models to generate a prediction of burst pressure and access the model fitness. Burst pressure data from FE analysis are generated as a validation model. Table 8 shows the burst pressure prediction and the error differences for model 11 in 5 different critical locations of the pipelines measured by distance, meter(m). The number after the label model is the number of realtered input data. As shown in the results, the model's input needs three modifications before it reaches a fit model. Fig.7 shows the ERF factor of the model 11-3 output compares with the output based on ASME B31G. There is a wide gap between both outputs as the ASME B31G shows all the defected points are not fit to service anymore. The differences in burst pressure for both outputs in average about $38 \mathrm{MPa}$. Fig. 8 shows the stress output from the Model 11-3 database compared to the FE of sample pipe at point $1420.38 \mathrm{~m}$. There is a slight difference in the stress area of the total body of the pipelines but the stress-strain at the defected area is matching.

The ANN model 11-3 has managed to predict the residual burst pressure with a small margin error when compared to pipeline FE data. Compared to the prediction model produced by Mohd et al.[2] and Wen et al.[14] based on AMSE B31G, this research's model gives the closest output to the actual burst pressure of the pipelines and prevents early failure pipe detection. Therefore, the final ANN data input of Model 11-3 as in Table 9 can be used for bursting pressure prediction for the aging corroded pipelines.

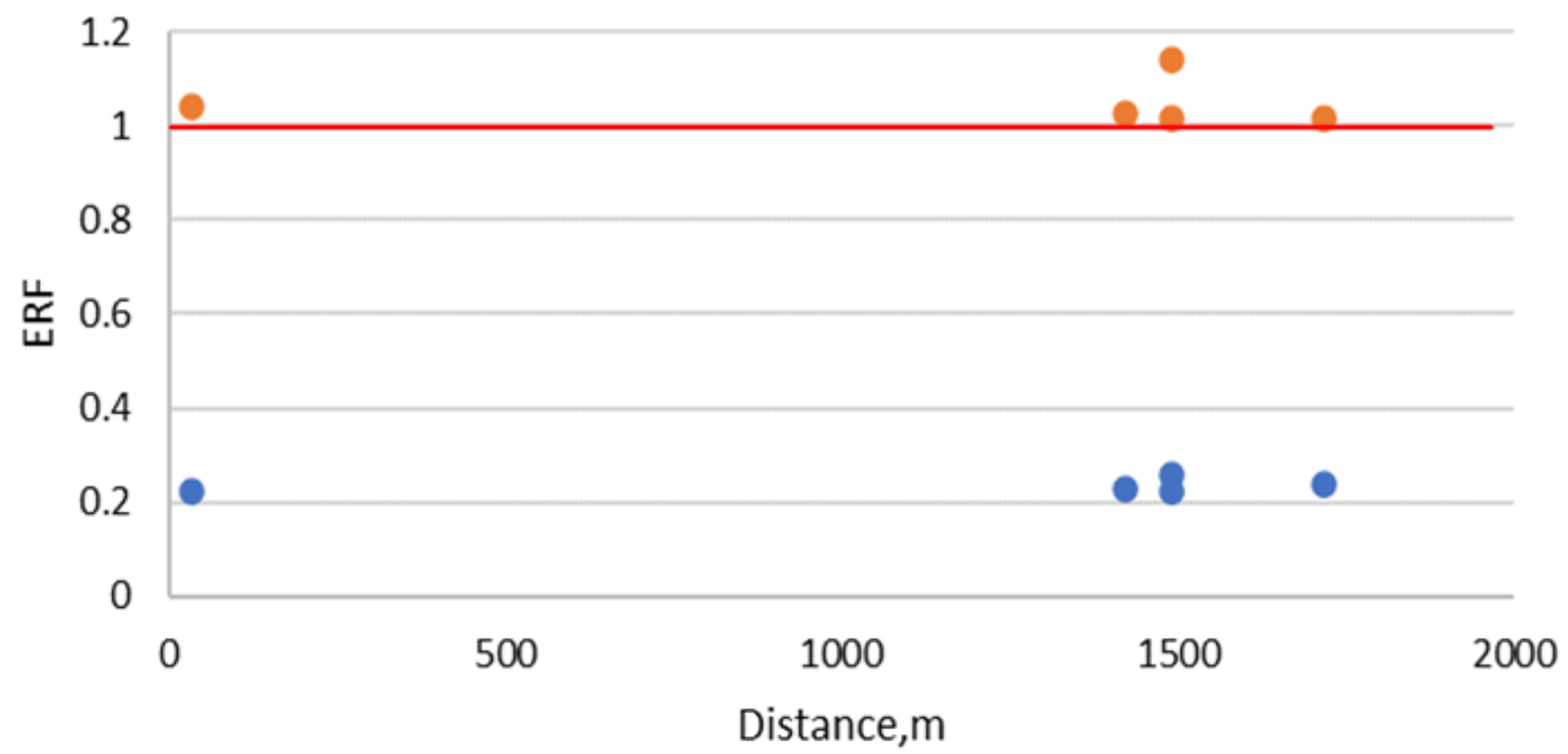

Model 11-3 ASME B31G

Figure 7. ERF output from Model 11-3 and ASME B31G 
FE point $1420.38 m$
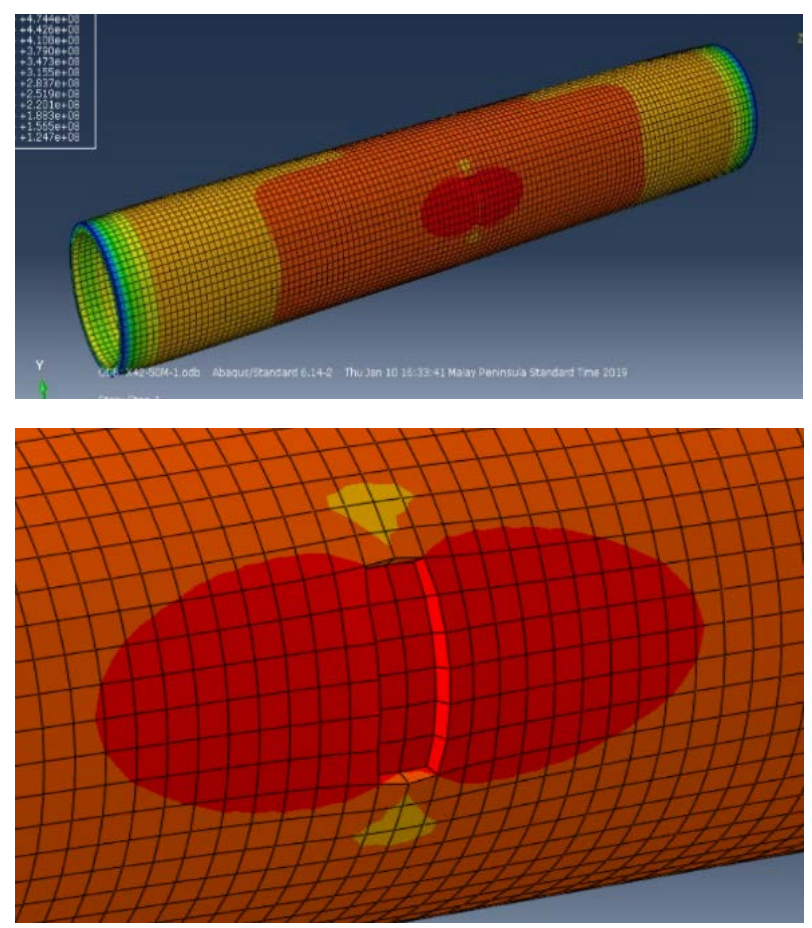

Figure 8. Finite element stress output

Table 9. ANN Design parameter of Model 11-3

\begin{tabular}{|c|c|}
\hline ANN Parameters & Details \\
\hline & Feedforward network \\
Network & $1^{\text {st }}$ layer $=5$ neurons \\
No. of layer and & $2^{\text {nd }}$ layer $=2$ neurons \\
neurons & Levenberg-Marquardt \\
Training function & $1^{\text {st }} \& 2^{\text {nd }}$ layer $=$ Logsig function \\
Activation function & Random \\
Data division & Average method \\
Normalization & Mean square error (MSE) \\
Performance & Mean absolute error (MAE) \\
& Training $=70 \%$ \\
Data distribution & Validation $=15 \%$ \\
& Testing $=15 \%$ \\
\hline
\end{tabular}

\section{Conclusions}

As for the concluding remarks, the study has successfully developed an alternative method to predict the burst pressure by using ANN and validated by the output from FE historical inspection pipelines data. This research is very important in providing strength pipelines output to engineers and saving a lot of time in preparing the time-consuming FE model. However, the model is restricted with a few criteria as:

FE from Model 11-3 database
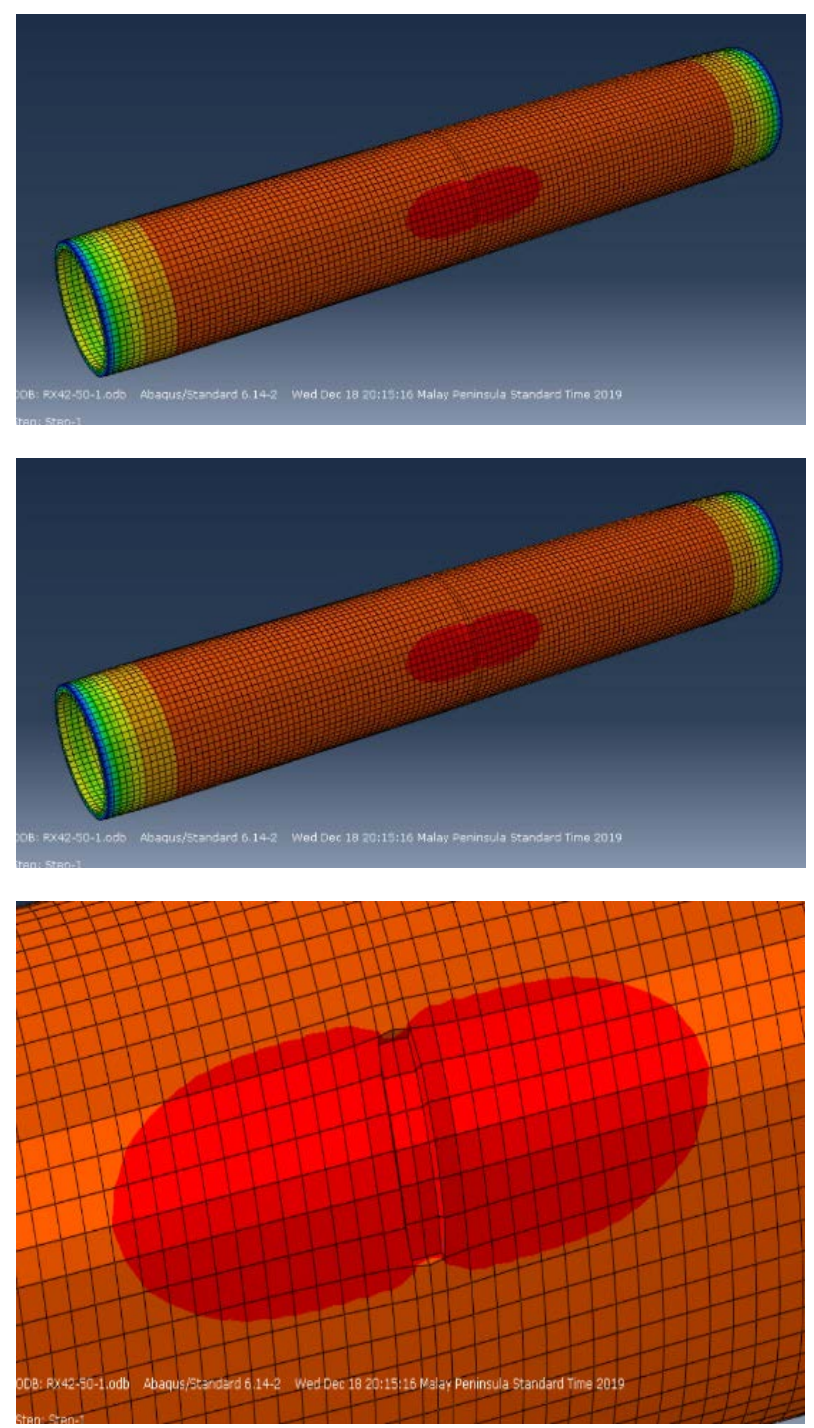

\begin{tabular}{|c|c|}
\hline ANN Parameters & Details \\
\hline Network & Feedforward network \\
No. of layer and & $1^{\text {st }}$ layer $=5$ neurons \\
neurons & $2^{\text {nd }}$ layer $=2$ neurons \\
Training function & Levenberg-Marquardt \\
Activation function & $1^{\text {st }} \& 2^{\text {nd }}$ layer = Logsig function \\
Data division & Random \\
Normalization & Average method \\
Performance & Mean square error (MSE) \\
& Mean absolute error (MAE) \\
Data distribution & Training $=70 \%$ \\
& Validation $=15 \%$ \\
& Testing $=15 \%$ \\
\hline
\end{tabular}

- The ANN model is analyzed with API 5L X42 type of pipelines with a specified diameter and data location in the South China Sea only. For other types of pipelines, new input should be accounted to be trained by the ANN model.

- Due to the limitation of data, the ANN model is strictly for single or splitting types of corrosion/defects. 


\section{Acknowledgments}

This research is supported by UiTM Fundamental Research Grant Scheme - 285944-298785 (Fundamental Research Grants Scheme, FRGS) by the Ministry of Higher Education, Malaysia.

\section{REFERENCES}

[1] J. K. Seo, Y. Cui, M. H. Mohd, Y. C. Ha, B. J. Kim, and J. K. Paik, A risk-based inspection planning method for corroded subsea pipelines, Ocean Eng., vol. 109, pp. 539-552, 2015.

[2] M. H. Mohd, B. J. Lee, Y. Cui, and J. K. Paik, Residual strength of corroded subsea pipelines subject to combined internal pressure and bending moment, Ships Offshore Struct., vol. 10, no. 5, pp. 554-564, 2015.

[3] S. D. V. Kumar, S. Karuppanan, and M. Ovinis, Failure pressure prediction of high toughness pipeline with a single corrosion defect subjected to combined loadings using artificial neural network (Ann), Metals (Basel)., vol. 11, no. 2, pp. 1-25, 2021.

[4] H. Liu, F. Khan, and P. Thodi, Revised burst model for pipeline integrity assessment, Eng. Fail. Anal., vol. 80, pp. 24-38, 2017.

[5] Y. Yang, F. Khan, P. Thodi, and R. Abbassi, Corrosion induced failure analysis of subsea pipelines, Reliab. Eng. Syst. Saf., vol. 159, pp. 214-222, 2017.

[6] R.-M. Chen, J.-S. Qiu, B.-Y. Liu, and G.-L. Ren, Research on residual strength of corrosive pressure pipelines based on burst failure, Chuan Bo Li Xue/Journal Sh. Mech., vol. 24, no. 7, pp. 925-933, 2020.

[7] M. Al-Amin and W. Zhou, Evaluating the system reliability of corroding pipelines based on inspection data, Struct. Infrastruct. Eng., vol. 10, no. 9, pp. 1161-1175, 2014.

[8] M. M. Din, N. Ithnin, A. M. Zain, N. M. Noor, M. M. Siraj, and R. M. Rasol, An artificial neural network modeling for pipeline corrosion growth prediction, ARPN J. Eng. Appl. Sci., vol. 10, no. 2, pp. 512-519, 2015.

[9] S. K. Sinha and M. D. Pandey, Probabilistic neural network for reliability assessment of oil and gas pipelines, Comput. Civ. Infrastruct. Eng., vol. 17, no. 5, pp. 320-329, 2002.

[10] A. Senouci, M. Elabbasy, E. Elwakil, B. Abdrabou, and T. Zayed, A model for predicting failure of oil pipelines, Struct. Infrastruct. Eng., vol. 10, no. 3, pp. 375-387, 2014.

[11] M. S. El-Abbasy, A. Senouci, T. Zayed, F. Mirahadi, and L. Parvizsedghy, Artificial neural network models for predicting condition of offshore oil and gas pipelines, Autom. Constr., vol. 45, pp. 50-65, 2014.

[12] S. A. Miran, Q. Huang, and H. Castaneda, Time-dependent reliability analysis of corroded buried pipelines considering external defects, J. Infrastruct. Syst., vol. 22, no. 3, 2016.

[13] W.-Z. Xu, C. B. Li, J. Choung, and J.-M. Lee, Corroded pipeline failure analysis using artificial neural network scheme, Adv. Eng. Softw., vol. 112, pp. 255-266, 2017.

[14] K. Wen, L. He, J. Liu, and J. Gong, An optimization of artificial neural network modeling methodology for the reliability assessment of corroding natural gas pipelines, $J$. Loss Prev. Process Ind., vol. 60, pp. 1-8, 2019.

[15] M. H. Bin Mohd, D. W. Kim, B. J. Lee, D. K. Kim, J. K. Seo, and J. K. Paik, On the burst strength capacity of an aging subsea gas pipeline, J. Offshore Mech. Arct. Eng., vol. 136, no. 4, 2014.

[16] Y. Chen, H. Zhang, J. Zhang, X. Liu, X. Li, and J. Zhou, Failure assessment of X80 pipeline with interacting corrosion defects, Eng. Fail. Anal., vol. 47, no. PA, pp. 6776, 2015.

[17] X. Li, Y. Bai, C. Su, and M. Li, Effect of interaction between corrosion defects on failure pressure of thin wall steel pipeline, Int. J. Press. Vessel. Pip., vol. 138, pp. 8-18, 2016.

[18] M. Hairil Mohd and J. K. Paik, Investigation of the corrosion progress characteristics of offshore subsea oil well tubes, Corros. Sci., vol. 67, pp. 130-141, 2013.

[19] M. N. Ilman and Kusmono, Analysis of internal corrosion in subsea oil pipeline, Case Stud. Eng. Fail. Anal., vol. 2, no. 1, pp. 1-8, 2014.

[20] G. De Masi, M. Gentile, R. Vichi, R. Bruschi, and G. Gabetta, Machine learning approach to corrosion assessment in subsea pipelines, in MTS/IEEE OCEANS 2015 - Genova: Discovering Sustainable Ocean Energy for a New World, 2015.

[21] Y. Kurtgoz, M. Karagoz, and E. Deniz, Biogas engine performance estimation using ANN, Eng. Sci. Technol. an Int. J., vol. 20, no. 6, pp. 1563-1570, 2017.

[22] M. R. Moghaddasi and M. Noorian-Bidgoli, ICA-ANN, ANN and multiple regression models for prediction of surface settlement caused by tunneling, Tunn. Undergr. Sp. Technol., vol. 79, pp. 197-209, 2018.

[23] M. Gethsiyal Augasta and T. Kathirvalavakumar, Reverse engineering the neural networks for rule extraction in classification problems, Neural Process. Lett., vol. 35, no. 2, pp. 131-150, 2012.

[24] C.-K. Oh, Y.-J. Kim, J.-H. Baek, Y.-P. Kim, and W.-S. Kim, Ductile failure analysis of API X65 pipes with notch-type defects using a local fracture criterion, Int. J. Press. Vessel. Pip., vol. 84, no. 8, pp. 512-525, 2007.

[25] M. H. Mohd, D. K. Kim, D. W. Kim, and J. K. Paik, A time-variant corrosion wastage model for subsea gas pipelines, Ships Offshore Struct., vol. 9, no. 2, pp. 161-176, 2014.

[26] S.-W. Gao, N. Shao, and L.-J. Yang, Determining the remaining strength of corroded pipelines with B31G code and finite element analysis theory, in 2010 International Conference on Measuring Technology and Mechatronics Automation, ICMTMA 2010, 2010, vol. 1, pp. 1097-1100.

[27] B. N. Leis and D. R. Stephens, Alternative approach to assess the integrity of corroded line pipe - Part I: Current status, in Proceedings of the International Offshore and Polar Engineering Conference, 1997, vol. 4, pp. 624-634. 
[28] DNV. Recommend Practic, RP-F101, Corroded pipelines. Det Norske Veritas, Norway; 2000
[29] PETRONAS.Pipeline inspection report. Kuala Lumpur: Petroliam Nasional Berhad (PETRONAS). 2011 